Šporčić, B., \& Glavak-Tkalić, R. (2018). The relationship between online gaming motivation, self-concept clarity and tendency toward problematic gaming. Cyberpsychology: Journal of Psychosocial Research on Cyberspace, 12(1), article 4. https://doi.org/10.5817/CP2018-1-4

\title{
The relationship between online gaming motivation, self-concept clarity and tendency toward problematic gaming
}

\author{
Berislav Šporčić1 \& Renata Glavak-Tkalić \\ ${ }^{1}$ Department for Forensic Psychiatry, University Psychiatric Hospital Vrapče, Zagreb, Croatia \& University of Split School of \\ Medicine, Split, Croatia \\ ${ }^{2}$ Institute of Social Sciences Ivo Pilar, Zagreb, Croatia
}

\begin{abstract}
The aim of this study was to explore the relationship between online gaming motivation, self-concept clarity and problematic online gaming. More specifically, the study investigated the mediating role of gaming motives between self-concept clarity and problematic online gaming. Data from 509 young adult ( $M=23.14, S D=4.66$ ) video game players from Croatia were analyzed. Problematic online gaming was positively correlated with social, competition, coping, fantasy and escape motives for playing online video games, and negatively with self-concept clarity. Hierarchical regression analyses revealed that escape motives and self-concept clarity were significant predictors of problematic online gaming after controlling for age and weekly gaming time. The results of the mediation model showed that self-concept clarity was both directly and indirectly (via escape motive) associated with problematic online gaming. The discussion addresses the issue of escapism in relation to self-concept clarity and as a factor in predicting problematic online gaming.
\end{abstract}

Keywords: Problematic online gaming; motives for playing online video games; self-concept clarity; internet gaming disorder; Croatia

\section{Introduction}

Playing video games is a very popular way of spending free time. It is currently one of the most widespread sources of entertainment, regardless of one's culture, age and gender. According to estimates, there are about 2.2 billion gamers in the world, and global industry revenue generated about $\$ 108$ billion in 2017 by the sale of video games and gaming equipment (Newzoo, 2017). With the increasing number of users the potential effects of video games have been continually debated. A number of studies address the potential benefits of playing video games, such as cognitive, motivational, emotional, and social (Granic, Loebel, \& Engels, 2014). However, other studies suggest that a loss of control over playing video games may lead to a series of negative consequences (e.g., depression, anxiety, conduct problems, aggression, lower academic achievement), and problems with a healthy amount of gaming (Andreassen et al., 2016; Caplan, Williams, \& Yee, 2009; Gentile et al., 2011; Kardefelt-Winther, 2014; Kim et al., 2016; Kuss \& Griffiths, 2012; Lemmens, Valkenburg, \& Peter, 2011). Considering that gaming population is on the increase, and therefore of significant importance for public health, the Diagnostic and Statistical Manual of Disorders DSM-V has proposed the diagnostic criteria for Internet Gaming Disorder (IGD) to define problematic gaming. It is classified under the conditions for further study of Section III as a predominantly behavioral addiction, similar to Gambling Disorder, and it is suggested that more evidence is necessary before it is included as a standard disorder in the DSM classification system (APA, 2013).

The international prevalence rates of problematic gaming reported in the studies using representative samples, ranged from 0.6\% (Müller at al., 2014) to 9.4\% (Turner at al., 2012). Inconsistent results on prevalence rates reflect 
variations in the conceptualization of problematic gaming, study population and design, as well as in the use of different assessment tools with different cut-off values (Király, Nagygyörgy, Koronczai, Griffiths, \& Demetrovics, 2015). In a systematic review by King, Haagsma, Delfabbro, Gradisar, and Griffiths (2013), 18 different screening instruments developed to assess problematic gaming were evaluated across 63 studies, and the authors concluded that no two instruments were alike in their theoretical orientation and ability to establish diagnostic features of problematic gaming. New instruments have been developed since, and several of them have been modelled on the nine IGD criteria in the DSM-V (APA, 2013). Studies evaluating the suggested IGD criteria using representative samples, have reported the IGD prevalence of $5.4 \%$ in a study of Dutch adolescents and adults (Lemmens, Valkenburg, \& Gentile, 2015), 1.2\% in a study of German adolescents (Rehbein, Kliem, Baier, Mößle, \& Petry, 2015) and 2.5\% in a study of Slovenian eighth-grade adolescents (Pontes, Macur, \& Griffiths, 2016).

\section{Motivation for Online Gaming}

Initial research into motivation for playing online games was conducted by Bartle (1996), who identified four principal reasons why people enjoy playing Multi-User Dungeons (MUD: the ancestors of Massively Multiplayer Online Role-Playing Games, MMORPG). ${ }^{1}$ Based on the players' motives, he classified them into four groups: those who strive to attain the desired goal (achievers), investigate around the game (explorers), socialize with other players (socializers) and those who want to dominate and act on other players (killers). However, Bartle has not performed any empirical testing of his model. Following this preliminary framework and based on Bartle's dimensions, Yee (2006) has tested a 40-item questionnaire on a sample of 3000 MMORPG players. Instead of the original four, Yee identified 10 motivational components and reduced them to three higher-level motivational dimensions: achievement (advancement, mechanics, competition), social (socializing, relationship, teamwork), and immersion (discovery, role-playing, customization, escapism). Finally, he classified the players into three groups based on the mentioned motivational dimensions. The limitations of the model, arising from its development on a specific sample of MMORPG players, as well as the possibility that other motivational dimensions may be involved, have encouraged a study by Demetrovics et al. (2011) comprising 3818 players of various genres. Seven motivational factors for online gaming were identified: social, escape, competition, coping, skill development, fantasy, and recreation, and they were used to develop the 27-item Motives for Online Gaming Questionnaire (MOGQ), the instrument we have employed in this study.

Different motives for gaming reflect differently on IGD. Among various associations between motivation for playing video games and IGD identified in the previous research, the association between escapism and IGD was found to be the most consistent (e.g., Kuss, Louws, \& Wiers, 2012; Yee, 2006; Zanetta Dauriat et al., 2011). Escapism refers to intentional detachment from the real world and avoidance of coping with everyday problems (Demetrovics et al., 2011). It is a facet of a higher-order motivating factor manifested in immersion (Yee, 2006). Kuss et al. (2012), Yee (2006), and Zanetta Dauriat et al. (2011) reported a positive association between the development of IGD and the motive of escapism in MMORPG players. Additionally, escapism was found to be the best predictor of IGD among the players of World of Warcraft (Billieux et al., 2013; Kardefelt-Winther, 2014). A positive association between escapism and IGD was also confirmed in other studies, and additional motives for playing online video games related to IGD were identified, such as motives of achievement, mastering game mechanics and socialization (Blinka \& Mikuška, 2014; Xu, Turel, \& Yuan, 2012; Zanetta Dauriat et al., 2011).

\section{Self-Concept Clarity and Virtual Worlds of Online Games}

Self-concept refers to a multidimensional, dynamic construct which is defined as a cognitive schema, the term used to describe an organized knowledge structure that incorporates a person's traits, values, episodic and semantic memories and controls the processing of self-relevant information (Greenwald \& Pratkanis, 1984; Kihlstrom et al., 1988). A person's self-concept contains many different self-schemas and provides an answer to the question "Who am I?" (Myers, 2009). Campbell et al. (1996) reported that people generally have a clear concept about who they are and what they are, and defined self-concept clarity as the extent to which the contents of the self are clearly and confidently articulated, consistent, and temporally stable. Video games provide opportunities for gamers to look for and clarify their self-concept. Matsuba (2006) found that self-concept clarity negatively correlates with internet use, suggesting that internet may be a useful tool in exploring and discovering one's identity. Self-concept clarity has been identified by researchers as a risk factor for the development of internet addiction in the individuals who tend to satisfy their social needs through virtual interactions (Israelashvili, Kim, \& 
Bukobza, 2012; Quinones \& Kakabadse, 2015a). Furthermore, Lee, Aiken and Hung (2012) found that gamers with lower self-concept clarity spend more time playing video games.

Virtual worlds of online video games could be described as simulated environments that digitally mimic the complex physical world, where users can interact with others and which provide opportunities to test multiple new identities through the use of avatar (Bainbridge, 2007). The avatar is a digital representation of person's self in the virtual world (Bailenson, Yee, Blascovich, \& Guadagno, 2008). Much attention has been focused on investigating avatars in online video games and their interference with a player's self-concept (Dieter et al., 2015; DiPietro \& Black, 2009). The research data suggest the possibility that problematic MMORPG players compensate for their poor sense of self by creating avatars with their own desired characteristics and skills (Bessière, Seay, \& Kiesler, 2007; Smahel, Blinka, \& Ledabyl, 2008). According to the Self-Discrepancy Theory (Higgins, 1987), one is naturally motivated to decrease discrepancy between the actual, ideal and ought self, because a discrepancy between the various self-concepts leads to emotional discomfort. A research by Przybylski et al. (2012) provides the most direct empirical support for the suggested relationship between video game identification, reduction of self-discrepancy and gaming enjoyment. The enjoyment in playing video games may be a strong source of intrinsic motivation, and it was concluded that video games had the greatest impact on a player's emotions when his actual self is brought into complete accord with his ideal self. The avatars typically represent a combination of a player's characteristics and qualities of actual and ideal self (Bessière et al., 2007; Leménager et al., 2013; Smahel et al., 2008). It was found that those with lower psychological well-being are more likely to create avatars similar to their ideal self (Bessière et al., 2007). Smahel et al. (2008) propose that identification with a character is a factor influencing addiction, and in the research by Leménager et al. (2013) a significantly smaller number of differences between ideal self and avatars was identified in addicted players in comparison with non-addicted players and naive participants. It can therefore be assumed that a poor self-concept in gamers may be a key factor in the development and maintenance of video game addiction, and that specific features of the virtual worlds may lead to the excessive use of internet and online gaming.

\section{Mediating Role of Motives for Video Game Playing}

The role of motives for playing video games as mediating factors in the development of problematic gaming has been explored in several studies. According to Király, Urbán et al. (2015) and Ballabio et al. (2017), psychiatric distress had both direct and indirect effects on problematic online gaming, via escape motive for playing (but also via competition and fantasy motives, respectively). Kardefelt-Winther (2014) demonstrated that escapism and achievement motives mediate the relationship between stress and excessive online gaming. Furthermore, motives for playing online video games seem to be mediators in the relationship between self-concept and IGD. Kwon, Chung, and Lee (2011) concluded that a discrepancy between ideal and actual self-concepts triggers negative moods, which leads to escapism and consequently to IGD, suggesting that the motive to escape from self and reality can be used to explain IGD. According to the study by Li, Liau, and Khoo (2011), depression mediated the relationship between actual-ideal discrepancies and escapism, and escapism in turn mediated the relationship between depression and IGD.

\section{The Present Study}

The empirical evidence from previous studies shows that there is a connection between gaming motivations and IGD. While many studies consistently confirm the association between the escapism and IGD, the findings are somewhat inconsistent about how other motives relate to IGD. To the best of our knowledge, no study has explored the relationship between self-concept clarity and IGD so far, and how are motives for playing video games related to these concepts remains unclear. Previous studies suggest that IGD can be explained as overregulated coping strategy of approaching ideal self and escaping from actual self. Therefore, the mediating role of motives for video game playing in understanding IGD should be further explored. In line with this, the aim of the present study was to investigate the relationship between online gaming motivations, self-concept clarity and IGD in a Croatian sample of online video game players. More specifically, the study investigated the mediating role of gaming motives in the relationship between self-concept clarity and IGD. 


\section{Methods}

\section{Participants and Procedure}

Inclusion criteria were online video game players aged 18 years and older from Croatia. The study was conducted via an online questionnaire using the snowball sampling method. Links to the survey were placed on various online video game forums in the Croatian language (HCL.hr Gaming Forum, Bug Online Forum and Forum.hr), Facebook groups and pages. Croatian language versions of all questionnaires were administered in accordance with the Croatian Psychological Chamber's Code of Ethics. Anonymity of the participants was guaranteed, and they took part in this study without receiving any form of compensation (e.g., financial, material, etc.). The survey took approximately 10 minutes to complete. Out of the initial number of 1089 online video game players who completed the survey, in the analysis were included 509 participants who met the age-related inclusion criteria (18 years and older) and provided complete and non-stereotyped answers (27 participants were excluded). The sample was predominantly male $(91.2 \%, n=464)$ with the age ranging from 18 to 40 years $(M=23.14, S D=4.66)$. Most of the participants (58.2\%) were university and secondary school students, $38.1 \%$ were employed, and $10 \%$ were unemployed.

\section{Measures}

Motives for Online Gaming Questionnaire (MOGQ; Demetrovics et al., 2011) is a 27-item self-report measure used to assess the full range of motives for online gaming. The items are measured on a 5-point Likert scale from "never" to "almost always/always", with higher scores indicating higher frequency of the respective motivational dimension. The 7 motivational dimensions assessed by MOGQ were: Social ("...because I can meet many different people"), Escape ("...to forget about unpleasant things or offenses"), Competition ("...because it is good to feel that I am better than others"), Coping ("...because it helps me get rid of stress"), Skill Development ("...because it improves my skills"), Fantasy ("...to be somebody else for a while"), and Recreation ("...because it is entertaining"). Each dimension is represented by 4 items except for the motive subscale Recreation which includes 3 items. The Cronbach's alpha reliability coefficients of MOGQ subscales were: Social $(\alpha=.80)$, Escape $(\alpha=.86)$, Competition ( $\alpha$ $=.86)$, Coping $(\alpha=.70)$, Skill Development $(\alpha=.92)$, Fantasy $(\alpha=.86)$, and Recreation $(\alpha=.66)$.

Internet Gaming Disorder Scale (IGD-9; Lemmens et al., 2015) is a 9-item dichotomous scale used to assess internet gaming disorder based on DSM-V diagnostic criteria for IGD. The measure is based on gaming over the past 12 months, and each item represents one of the criteria included in DSM-V. Example of an IGD-9 item: "During the last year have you lost interest in hobbies or other activities because gaming is all you wanted to do?" A participant's score on the scale is calculated as a composite score of affirmative answers, ranging from 0 to 9 . Higher scores on the IGD-9 scale indicate more severe cases of IGD (APA, 2013). In the present study the IGD-9 had acceptable reliability with Cronbach's alpha $\alpha=.67$.

Self-Concept Clarity Scale (SCC; Campbell et al., 1996) was used to measure clarity and cohesiveness of the characteristics within the self-concept. The scale consists of 12 statements, e.g., "In general, I have a clear sense of who I am and what I am", which were assessed on a 5-point Likert scale from strongly disagree to strongly agree. Higher scores on the Self-Concept Clarity Scale indicate greater self-concept clarity. In the current study, Cronbach's alpha was $a=.87$.

Gaming behavior. The questions addressing gaming behavior included types of games, playing platform, onlineoffline playing and the time spent playing games during the week and on weekends.

Socio-demographic variables. Background information about participants' characteristics included age, gender and employment status. 


\section{Results}

As shown in Table 1, the average amount of time the participants spent playing video games was $28.86(S D=20.31)$ hours per week. Majority of players played video games from multiple game genres. The most prevalent were the following games: first-person shooter games, role-playing games, adventures, MOBA and MMORPG games (54.8\%, $49.7 \%, 41.8 \%, 36 \%$ and $33.4 \%$, respectively). The participants reported high motivation for online gaming on all dimensions of motives. The most prominent among the motives was Recreation $(M=4.71 ; S D=0.5)$, and the least prominent Escape $(M=2.77 ; S D=1.13)$. On average, the participants in our sample have displayed 3 IGD symptoms on the IGD-9 scale $(M=3.10 ; S D=2.13)$, which reveals their tendency to engage in problematic video game playing. According to DSM-V (cut-off point 5 or more criteria) the IGD criteria were met by $23.8 \%$ of participants. A shift of the average score toward higher values on the Self-Concept Clarity scale suggests that, on average, the participants have clear and well defined beliefs about themselves (Table 1).

Table 1. Descriptive Statistics in Measures of IGD, Self-Concept Clarity, Motives for Online Gaming, and Weekly Gaming Time.

\begin{tabular}{lcccc}
\hline & $\boldsymbol{M}$ & $\boldsymbol{S D}$ & TR & $\mathbf{a}$ \\
\hline IGD symptoms & 3.10 & 2.13 & $0-9$ & .67 \\
Self-Concept Clarity & 44.93 & 9.76 & $12-60$ & .87 \\
Social & 2.94 & 0.96 & $1-5$ & .80 \\
Escape & 2.77 & 1.13 & $1-5$ & .86 \\
Competition & 3.36 & 1.01 & $1-5$ & .86 \\
Coping & 3.43 & 0.85 & $1-5$ & .70 \\
Skill Development & 3.37 & 1.14 & $1-5$ & .92 \\
Fantasy & 2.88 & 1.18 & $1-5$ & .86 \\
Recreation & 4.71 & 0.50 & $1-5$ & .66 \\
Weekly gaming time $(\mathrm{h})$ & 28.86 & 20.31 & - & - \\
Age & 23.14 & 4.66 & $18-40$ & - \\
\hline
\end{tabular}

Note: IGD - internet gaming disorder, a - Cronbach alpha coefficient of reliability.

Correlations shown in Table 2 indicate that IGD was significantly negatively associated with the self-concept clarity. A positive association was determined between IGD and motivational dimensions of escape, fantasy, coping, sociability and competition, and the highest correlation was observed between IGD and the motive of escape.

Table 2. Correlations between Measures of IGD, Self-Concept Clarity, Motives for Online Gaming, Weekly Gaming Time, and Age.

\begin{tabular}{|c|c|c|c|c|c|c|c|c|c|c|c|}
\hline & 1 & 2 & 3 & 4 & 5 & 6 & 7 & 8 & 9 & 10 & 11 \\
\hline 1. IGD symptoms & 1 & $-.388 * \star$ & $.217^{\star \star}$ & $.446 * \star$ & $.146 * \star$ & $.300 * \star$ & .086 & $.307 * \star$ & .026 & $.224 * \star$ & $-.088 * \star$ \\
\hline 2. Self-Concept & & 1 & -.076 & $-.390 * \star$ & -.084 & $-.186 * \star$ & .001 & $-.285 * \star$ & -.029 & $-.225 * *$ & $.232 * *$ \\
\hline 3. Social & & & 1 & $.352 * \star$ & $.254 * \star$ & $.370 * \star$ & $.488^{\star \star}$ & $.346 * \star$ & $.165^{\star \star}$ & $.226 * \star$ & -.084 \\
\hline 4. Escape & & & & 1 & $.256^{\star *}$ & $.606 * \star$ & $.269 * \star$ & $.619 * \star$ & .059 & $.161 * *$ & $-.128 * *$ \\
\hline 5. Competition & & & & & 1 & $.295 * \star$ & $.276 * \star$ & $.246 * \star$ & $.137^{\star \star}$ & $.174 * *$ & -.070 \\
\hline 6. Coping & & & & & & 1 & $.518 * \star$ & $.509 * \star$ & $.243 * \star$ & $.122 * \star$ & -.046 \\
\hline 7. Skill Development & & & & & & & 1 & $.325 * \star$ & $.188^{* *}$ & $.148 * *$ & $-.096 *$ \\
\hline 8. Fantasy & & & & & & & & 1 & $.186^{* \star}$ & $.152 * *$ & $-.132 * *$ \\
\hline 9. Recreation & & & & & & & & & 1 & .052 & -.001 \\
\hline 10. Weekly gaming & & & & & & & & & & 1 & $-.149 * *$ \\
\hline 11. Age & & & & & & & & & & & 1 \\
\hline
\end{tabular}

Note: IGD - internet gaming disorder, ${ }^{\star} p<.05,{ }^{* \star} p<.01$.

In order to determine the association between motivational dimensions, self-concept clarity and IGD, a two-step hierarchical linear regression analysis was conducted (Table 3). A score on the IGD-9 scale was used as the dependent variable, and it was treated as an ordinal variable in the analysis. In the first step, predictors of IGD were participants' age and weekly gaming time, and in the second step, the IGD predictors were scores on 
motivational dimensions for online gaming and self-concept clarity scales. Collectively, all variables accounted for $26.3 \%$ of variance in the participants' IGD scores. In the first step of the regression analysis, controlled variables accounted for $5.3 \%$ variance of IGD and therefore, both the player's age and weekly gaming time were significant predictors of IGD; younger age and longer weekly gaming time were associated with greater likelihood of IGD. Addition of the second block of predictors accounted for a significant increase of $22.4 \%$ in the variance in IGD scores. The motive of escape and self-concept clarity were significant predictors of problematic online gaming, with higher levels of the escape motive and lower self-concept clarity associated with greater likelihood of IGD.

Table 3. Hierarchical Regression Analyses Predicting Internet Gaming Disorder (IGD).

\begin{tabular}{|c|c|c|c|c|c|c|}
\hline & $\beta$ & $t$ & $R$ & $(\operatorname{adj}) R^{2}$ & $\Delta R^{2}$ & $F$ \\
\hline Model 1 & & & $.231 * *$ & $.050 * *$ & $.053^{* *}$ & $14.246 * *$ \\
\hline Age & $-.056 *$ & -1.280 & & & & \\
\hline Weekly gaming time & $.216 * *$ & 4.933 & & & & \\
\hline Model 2 & & & $.527 * \star$ & $.263^{* \star}$ & $.224^{\star \star}$ & $19.110^{* *}$ \\
\hline Age & -.022 & -.558 & & & & \\
\hline Weekly gaming time & $.111 * *$ & 2.734 & & & & \\
\hline Social & .089 & 1.929 & & & & \\
\hline Escape & $.268^{* *}$ & 4.638 & & & & \\
\hline Competition & .015 & 0.376 & & & & \\
\hline Coping & .089 & 1.595 & & & & \\
\hline Skill Development & -.097 & -1.957 & & & & \\
\hline Fantasy & .015 & 0.285 & & & & \\
\hline Recreation & -.012 & -0.302 & & & & \\
\hline Self-Concept Clarity & $-.234 * \star$ & -5.382 & & & & \\
\hline
\end{tabular}

Note: ${ }^{*} p<.05,{ }^{* *} p<.01$.

Additionally, the study investigated how gaming motives mediate the relationship between self-concept clarity and IGD. The PROCESS macro, model 4 (Hayes, 2012) was used with 10,000 bootstrap estimates to construct 95\% biascorrected confidence intervals (Cls; significant if not containing zero). Results of the mediation model (Figure 1) showed that self-concept clarity was both directly and indirectly (via escape motive) associated with IGD. Selfconcept clarity had a significant direct effect on IGD $(B=-0.26, p<.01)$ as well as on the following motives for online video gaming: escape $(B=-0.39, p<.01)$, coping $(B=-0.19, p<.01)$ and fantasy $(B=-0.29, p<.01)$. Regarding the relationship between motivational factors and IGD, escape $(B=0.26, p<.01)$ and social $(B=0.11, p<.01)$ motives demonstrated weak to moderate associations with total score on IGD scale. Regarding the indirect effects between self-concept clarity and IGD, one path was significant: self-concept clarity via escape motive to IGD ( $ß=-0.1, p<$ .01). The mediation pathways composed a total standardized indirect effect size of $-0.14(p<.01)$ accounting for $35 \%$ of the total effect. The full model explained $26.8 \%$ variance of the IGD score.

\section{Discussion}

The aim of this study was to investigate the relationship between individual motivations for online gaming, selfconcept clarity and tendency toward problematic gaming. The participants in our sample reported on average 3 IGD symptoms, which indicates the tendency toward problematic playing of video games, whereas $23.8 \%$ of them met the IGD criteria as set forth in DSM-V. Moreover, the participants expressed high motivation on all the dimensions of motivation for playing online video games. Considering that participants actively participate on different gaming forums and Facebook groups connected with video games, this finding could be explained by the way the sample was selected, and also by the criteria applied. All of the participants are involved in a gaming subculture which implies the presence of greater interest and motivation for playing video games. In addition, we can assume that their gaming is excessive, and consequently, they may experience more problems related to online gaming which results in higher numbers of reported IGD symptoms as compared to video game players who are not involved in gaming subculture or community.

The results of multiple regression analysis point to weekly gaming time, escape motive and self-concept clarity as significant predictors of IGD. Additionally, results of the mediation model suggest that self-concept clarity is both 
directly and indirectly (via escape motivation to play) negatively associated with IGD. Playing online video games to escape from the real world and to avoid dealing with everyday problems seems to be a motivation related with self-concept clarity and predicting IGD. In this research the escape motive proved as the best predictor of IGD which is in accordance with other studies (Billieux et al., 2013; Demetrovics et al., 2011; Kardefelt-Winther, 2014; Kuss et al., 2012; Xu et al., 2012; Yee, 2006; Zanetta Dauriat et al., 2011), where escapism consistently emerged as a significant motivational predictor of negative outcomes resulting from online gaming. For individuals motivated by escapism online video games provide a broad range of possibilities to withdraw from the real world into the virtual worlds of fantasy.

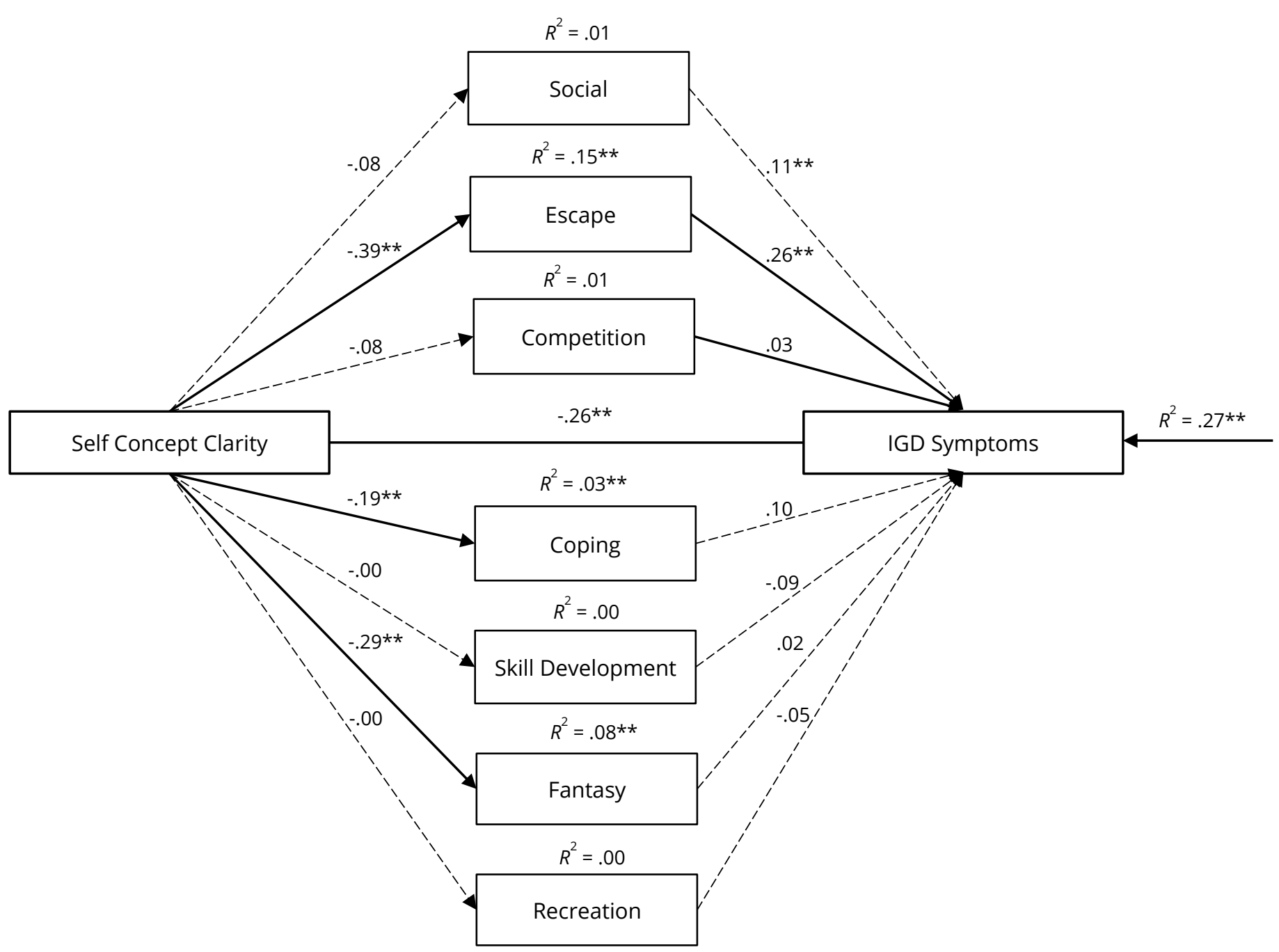

Figure 1. Mediation model with standardised path coefficients depicting the relationship between self-concept clarity, motives for online gaming, and internet gaming disorder. Legend: IGD - internet gaming disorder. Simple arrows present significant path coefficients and dashed arrows non-significant path coefficients. * $p<.05, * * p<.01$.

To the authors' knowledge, the relationship between self-concept clarity and IGD has not been studied yet, but several researches have revealed a significant correlation between the self-concept clarity and Internet addiction (Israelashvili et al., 2012; Matsuba, 2006; Quinones \& Kakabadse 2015a; Quinones \& Kakabadse 2015b). According to the findings of this research, players' self-concept clarity was significantly related to IGD and it was a significant predictor of IGD. Lower levels of self-concept clarity predicted a higher number of IGD symptoms, suggesting that players with a less clear self-concept engage in playing video games to achieve a temporary sense of certainty, stability, identity and control that is often lacking in the other areas of their lives, and as a consequence, this may lead to excessive and problematic video games playing. Based on the models of self-perception and self-concept consistent with a social psychological perspective, Klimmt, Hefner, \& Vorderer (2009) proposed that players deal with characters or take on social roles through the process of identification. Hence, it is possible that players, when identifying with a game character or avatar, temporarily alter their self-perception and their self-concept, and in particular when identification with a game character is appealing. For the moment, a player may feel like a character within the video game and attribute the character-prominent properties to himself, such as strength, 
courage, social status, charisma. Another relevant factor is linked with the Social Identity Theory (Tajfel \& Turner, 1985) and explanation that individuals define their self-concept through interrelation with social referents, such as work groups, organizations, and ethnicities. A sense of belonging to a specific group of players, developed by players within a guild in role-playing games or clans in some competitive games, may contribute to defining a sense of identity in video game players. Guegan, Moliner, and Buisine (2015) examined the process of identification among MMORPG players in line with the social identity framework and revealed that being a player and being a member of a guild directly contribute to the social identity. Moreover, a sense of belonging to gaming community may activate a dual system of identification: online during engagement within a game, and offline, as members of a gaming community (Badrinarayanan, Sierra, \& Martin, 2015).

As explained earlier, it is possible that players with a less clear self-concept engage in playing video games because an experience of being immersed into different roles offered within a game, or a possibility to create an avatar as a representation of one's ideal self with a clearly defined identity (Bessière et al., 2007; Leménager et al., 2013; Przybylski et al. 2012), helps them to develop a clearer concept of themselves. This gives them a temporary detachment from reality and their actual self, and therefore may lead to excessive and problematic video games playing. Hence, during exposure to video games, enjoyment or reducing negative emotions due to identification with a game character may be theoretically based in the reduction of self-discrepancies. Such reduction or complete removal of self-discrepancies between actual and ideal self is accompanied by positive experiences (Higgins, 1987), which then contribute to enhanced enjoyment in video games and higher intrinsic motivation at the moment when there is a match between a player's impression of himself and his concept of his ideal self for the duration of game exposure (Przybylski et al., 2012). For individuals with a poor sense of selves, process of identification with a game character, reduction of self-discrepancies and social identity formation through gaming community, or guilds and clans in virtual world of video games, can be seen as a form of escapism. The findings from the present study, suggesting that gaming for the individuals with low self-concept clarity may serve as a function of escape and avoidance of oneself which can lead to IGD, reveal that escapism mediate the relationship between self-concept clarity and IGD. Furthermore, the associations between self-concept clarity and coping and fantasy motives, observed in the mediation model, deserve attention. Even though coping (channeling distress, aggression and improving mood) and fantasy (stepping out of one's usual identity, trying new identities in a different fantasy world, and trying things that one cannot do in real life), do not mediate the association between self-concept clarity and IGD, their significant association with self-concept clarity is a finding that contributes to the previously mentioned explanation of escaping from oneself. These results are consistent with the those of Kwon et al. (2011) suggesting that IGD is induced as a way to escape from oneself and reality.

In various researches, the reported amount of time spent playing video games consistently shows significant associations with IGD (Choo et al., 2010; Gentile, 2009; Kuss et al., 2012; Porter, Starcevic, Berle, \& Fenech, 2010; Yee, 2006; Zanetta Dauriat et al., 2011). The obtained correlations are generally low to moderate, as well as in this research. It seems that more time spent in playing video games increases likelihood of developing problems that cause difficulties in everyday functioning. In this research, the regression analysis revealed that weekly time spent in playing online video games is a significant predictor of IGD, but after including the motives for playing and selfconcept clarity in the second step of analysis, the impact of time spent playing online video games decreased. Therefore, motives for playing video games and self-concept clarity could be considered better predictors of IGD than the amount of time spent in video games playing. The results are consistent with the previous researches which suggest that the amount of time spent in playing is not the most important factor for IGD explanation (Choo et al., 2010; Griffiths, 2010; Kirby, Jones, \& Copello, 2014; Kuss et al., 2012; Peng \& Liu, 2010).

When discussing the results of this study, certain methodological limits should be taken into account. The main limit is the very nature of the sample; it was a non-probability convenient sample which makes generalization of the results more difficult. Also, the research was conducted online, so that participants and researchers were not in a direct contact and there was no opportunity to clarify any ambiguity that have arisen during the survey in order to reduce likelihood of wrong answers due to difficulties in understanding questions. Furthermore, the study was cross-sectional which prevents conclusions on causal relations between the investigated variables.

Based on the results of this research some practical implications of the research could be discussed. The findings suggest that excessive playing of online video games in order to avoid real life difficulties, which are escapism motives, may be related to problematic gaming. Additionally, our results suggest that for the prevention or 
recovery from problematic online gaming, to reduce only the time spent in playing is not an efficient solution. From a practical standpoint, exploring the motives for online gaming at both individual and group levels may be helpful as a direct contribution in the preparations of prevention and treatment programs related to problematic gaming behavior.

Further research on this topic should address the status of the phenomenon and its possible inclusion as a separate disorder in the future revisions of the Diagnostic and Statistical Manual of Mental Disorders (DSM). In addition, suitability of the criteria proposed for identification of problematic gaming derived from substanceabuse criteria should be evaluated. In this research, the participants reported on average 3 IGD symptoms, and according to Lemmens et al. (2015) they could be identified as at-risk gamers. Among our participants $23.8 \%$ were found to meet the DSM-V criteria that are currently under consideration for the diagnosis of IGD (APA, 2013). According to Lemmens et al. (2015) they could be identified as disordered gamers. The question that needs to be answered is whether they really are at-risk gamers or disorderd gamers, or they are inappropriately categorized as such due to inadequate criteria? Depending on this, prevalence rates may be unrealistic and unreliable. There is an ongoing debate in the scientific community on the proposed IGD criteria, but the consensus has not been reached yet (Ballabio et al., 2017; Hellman, Schoenmakers, Nordstorm, \& van Holst, 2013; Király, Griffits, \& Demetrovics, 2015). Because of the need to address the nature of the problem, gaming disorder was defined for the first time in the beta draft of the 11th Revision of the International Classification of Diseases (ICD-11) (Aarseth et al., 2017; Saunders et al., 2017). However, more research is needed to establish clear diagnostic criteria for IGD, as well as to develop standard diagnostic tools for measuring problematic gaming and resulting functional impairment.

Future studies should employ longitudinal designs that include additional variables of psychological wellbeing in order to determine possible risk factors for the development and consequences of problematic video games playing. Likewise, future researches could be focused on assessment and comparison of motives for playing between the different genres of video games, which was not addressed in this research. More research should be undertaken to improve our understanding of the relationship between self-concept, motivation for playing and problematic gaming, with a specific focus on assessing different self-concept domains along with self-concept clarity, including self-esteem, emotional competence, and ideal-real discrepancy.

\section{Notes}

1. Text-based, multiplayer real-time games preceding MMORPG where interaction is exclusively achieved through text descriptions and exchange of textual messages.

\section{References}

Aarseth, E., Bean, A. M., Boonen, H., Colder Carras, M., Coulson, M., Das, D., ... Haagsma, M. C. (2017). Scholars' open debate paper on the World Health Organization ICD-11 Gaming Disorder proposal. Journal of Behavioral Addictions, 6, 267-270. https://doi.org/10.1556/2006.5.2016.088

American Psychiatric Association. (2013). Diagnostic and statistical manual of mental disorders (5th ed.). Washington, DC: Author.

Andreassen, C. S., Billieux, J., Griffiths, M. D., Kuss, D. J., Demetrovics, Z., Mazzoni, E., \& Pallesen, S. (2016). The relationship between addictive use of social media and video games and symptoms of psychiatric disorders: A large-scale cross-sectional study. Psychology of Addictive Behaviors, 30, 252-262.

https://doi.org/10.1037/adb0000160

Badrinarayanan, V. A., Sierra, J. J., \& Martin, K. M. (2015). A dual identification framework of online multiplayer video games: The case of massively multiplayer online role playing games (MMORPGs). Journal of Business Research, 68,1045-1052. https://doi.org/10.1016/j.jbusres.2014.10.006

Bainbridge, W. S. (2007). The scientific research potential of virtual worlds. Science, 317, 472-476.

https://doi.org/10.1126/science.1146930 
Bailenson, J. N., Yee, N., Blascovich, J., \& Guadagno, R. E. (2008). Transformed social interaction in mediated interpersonal communication. In E. Konijn, S. Utz, M. Tanis, \& S. Barnes (Eds.), Mediated interpersonal communication (pp. 77-99). New York, NY: Routledge.

Ballabio, M., Griffiths, M. D., Urbán, R., Quartiroli, A., Demetrovics, Z., \& Király, O. (2017). Do gaming motives mediate between psychiatric symptoms and problematic gaming? An empirical survey study. Addiction Research \& Theory, 25, 397-408. https://doi.org/10.1080/16066359.2017.1305360

Bartle, R. (1996). Hearts, clubs, diamonds, spades: Players who suit MUDs. Journal of MUD research, 1(1), 19.

Bessière, K., Seay, A. F., \& Kiesler, S. (2007). The ideal elf: Identity exploration in World of Warcraft. CyberPsychology \& Behavior, 10, 530-535. https://doi.org/10.1089/cpb.2007.9994

Billieux, J., Van der Linden, M., Achab, S., Khazaal, Y., Paraskevopoulos, L., Zullino, D., \& Thorens, G. (2013). Why do you play World of Warcraft? An in-depth exploration of self-reported motivations to play online and in-game behaviours in the virtual world of Azeroth. Computers in Human Behavior, 29, 103-109.

https://doi.org/10.1016/j.chb.2012.07.021

Blinka, L., \& Mikuška, J. (2014). The role of social motivation and sociability of gamers in online game addiction. Cyberpsychology: Journal of Psychosocial Research on Cyberspace, 8(2), article 6. http://dx.doi.org/10.5817/CP20142-6

Campbell, J. D., Trapnell, P. D., Heine, S. J., Katz, I. M., Lavallee, L. F., \& Lehman, D. R. (1996). Self-concept clarity: Measurement, personality correlates, and cultural boundaries. Journal of Personality and Social Psychology, 70, 141-156. https://doi.org/10.1037/0022-3514.70.6.1114

Caplan, S., Williams, D., \& Yee, N. (2009). Problematic Internet use and psychosocial well-being among MMO players. Computers in Human Behavior, 25, 1312-1319. https://doi.org/10.1016/j.chb.2009.06.006

Choo, H., Gentile, D., Sim, T., Li, D. D., Khoo, A., \& Liau, A. (2010). Pathological video-gaming among Singaporean youth. Annals Academy of Medicine, 39, 822-829.

Demetrovics, Z., Urbán, R., Nagygyörgy, K., Farkas, J., Zilahy, D., Mervó, B., \& Harmath, E. (2011). Why do you play? The development of the motives for online gaming questionnaire (MOGQ). Behavior Research Methods, 43, 814825. https://doi.org/10.3758/s13428-011-0091-y

Dieter, J., Hill, H., Sell, M., Reinhard, I., Vollstädt-Klein, S., Kiefer, F., ... Leménager, T. (2015). Avatar's neurobiological traces in the self-concept of massively multiplayer online role-playing game (MMORPG) addicts. Behavioral Neuroscience, 129, 8-17. https://doi.org/10.1037/bne0000025

DiPietro, J. C., \& Black, E. W. (2009). Visual analysis of avatars in gaming environment. In R. E. Ferdig (Ed.), Handbook of research on effective electronic gaming in education (pp. 606-620). Hershey, PA: Information Science Reference.

Gentile, D. (2009). Pathological video-game use among youth ages 8 to 18: A national study. Psychological Science, 20, 594-602. https://doi.org/10.1111/j.1467-9280.2009.02340.x

Gentile, D. A., Choo, H., Liau, A., Sim, T., Li, D., Fung, D., \& Khoo, A. (2011). Pathological video game use among youths: A two-year longitudinal study. Pediatrics, 127, 319-329. https://doi.org/10.1542/peds.2010-1353

Granic, I., Lobel, A., \& Engels, R. C. (2014). The benefits of playing video games. American Psychologist, 69, 66-78. https://doi.org/10.1037/a0034857

Greenwald, A. G., \& Pratkanis, A. R. (1984). The self. In R. S. Wyer Jr. \& T. K. Srull (Eds.), Handbook of social cognition (Vol. 3, pp. 129-178). Hiilsdale, NJ: Erlbaum.

Griffiths, M. D. (2010). The role of context in online gaming excess and addiction: Some case study evidence. International Journal of Mental Health and Addiction, 8, 119-125. https://doi.org/10.1007/s11469-009-9229-x

Guegan, J., Moliner, P., \& Buisine, S. (2015). Why are online games so self-involving: A social identity analysis of massively multiplayer online role-playing games. European Journal of Social Psychology, 45, 349-355.

https://doi.org/10.1002/ejsp.2103 
Hayes, A. F. (2012). PROCESS: A versatile computational tool for observed variable mediation, moderation, and conditional process modeling. Retrieved from http://www.afhayes.com/public/process2012.pdf

Hellman, M., Schoenmakers, T. M., Nordstrom, B. R., \& van Holst, R. J. (2013). Is there such a thing as online video game addiction? A cross-disciplinary review. Addiction Research \& Theory, 21, 102-112.

https://doi.org/10.3109/16066359.2012.693222

Higgins, E. T. (1987). Self-discrepancy: A theory relating self and affect. Psychological Review, 94, 319-340. https://doi.org/10.1037/0033-295X.94.3.319

Israelashvili, M., Kim, T., \& Bukobza, G. (2012). Adolescents' over-use of the cyber world-Internet addiction or identity exploration? Journal of Adolescence, 35, 417-424. https://doi.org/10.1016/j.adolescence.2011.07.015

Kardefelt-Winther, D. (2014). Problematizing excessive online gaming and its psychological predictors. Computers in Human Behavior, 31, 118-122. https://doi.org/10.1016/j.chb.2013.10.017

Kihlstrom, J. E., Cantor, N., Albright, J. S., Chew, B. R., Klein, S. B., \& Neidenthal, P. M. (1988). Information processing and the study of the self. In L. Berkowitz (Ed.), Advances in experimental social psychology (Vol. 21, pp. 159-187). San Diego, CA: Academic Press.

Kim, N. R., Hwang, S. S. H., Choi, J. S., Kim, D. J., Demetrovics, Z., Király, O., ... Choi, S. W. (2016). Characteristics and psychiatric symptoms of Internet Gaming Disorder among adults using self-reported DSM-5 criteria. Psychiatry Investigation, 13, 58-66. https://doi.org/10.4306/pi.2016.13.1.58

King, D. L., Haagsma, M. C., Delfabbro, P. H., Gradisar, M., \& Griffiths, M. D. (2013). Toward a consensus definition of pathological video-gaming: A systematic review of psychometric assessment tools. Clinical Psychology Review, 33, 331-342. https://doi.org/10.1016/j.cpr.2013.01.002

Kirby, A., Jones, C., \& Copello, A. (2014). The impact of massively multiplayer online role playing games (MMORPGs) on psychological wellbeing and the role of play motivations and problematic use. International Journal of Mental Health and Addiction, 12, 36-51. https://doi.org/10.1007/s11469-013-9467-9

Király, O., Griffiths, M. D., \& Demetrovics, Z. (2015). Internet gaming disorder and the DSM-5: Conceptualization, debates, and controversies. Current Addiction Reports, 2, 254-262. https://doi.org/10.1007/s40429-015-0066-7

Király, O., Nagygyörgy, K., Koronczai, B., Griffiths, M. D., \& Demetrovics, Z. (2015). Assessment of problematic internet use and online video gaming. In E. Aboujaoude \& V. Starcevic (Eds.), Mental health in the digital age: Grave dangers, great promise (pp.46-68). Oxford: Oxford University Press.

Király, O., Urbán, R., Griffiths, M. D., Ágoston, C., Nagygyörgy, K., Kökönyei, G., \& Demetrovics, Z. (2015). The mediating effect of gaming motivation between psychiatric symptoms and problematic online gaming: An online survey. Journal of Medical Internet Research, 17, e88. https://doi.org/10.2196/jmir.3515

Klimmt, C., Hefner, D., \& Vorderer, P. (2009). The video game experience as "true" identification: A theory of enjoyable alterations of players' self-perception. Communication Theory, 19, 351-373.

https://doi.org/10.1111/j.1468-2885.2009.01347.x

Kuss, D. J., \& Griffiths, M. D. (2012). Internet gaming addiction: A systematic review of empirical research. International Journal of Mental Health and Addiction, 10, 278-296. https://doi.org/10.1007/s11469-011-9318-5

Kuss, D. J., Louws, J., \& Wiers, R. W. (2012). Online gaming addiction? Motives predict addictive play behavior in Massively Multiplayer Online Role-Playing Games. Cyberpsychology, Behavior, and Social Networking, 15, 480-485. https://doi.org/10.1089/cyber.2012.0034

Kwon, J. H., Chung, C. S., \& Lee, J. (2011). The effects of escape from self and interpersonal relationship on the pathological use of internet games. Community Mental Health Journal, 47, 113-121.

https://doi.org/10.1007/s10597-009-9236-1

Lee, C., Aiken, K. D., \& Hung, H. C. (2012). Effects of college students' video gaming behavior on self-concept clarity and flow. Social Behavior and Personality: An International Journal, 40, 673-679.

https://doi.org/10.2224/sbp.2012.40.4.673 
Leménager, T., Gwodz, A., Richter, A., Reinhard, I., Kämmerer, N., Sell, M., \& Mann, K. (2013). Self-concept deficits in massively multiplayer online role-playing games addiction. European Addiction Research, 19, 227-234.

https://doi.org/10.1159/000345458

Lemmens, J. S., Valkenburg, P. M., \& Peter, J. (2011). The effects of pathological gaming on aggressive behavior. Journal of Youth and Adolescence, 40, 38-47. https://doi.org/10.1007/s10964-010-9558-x

Lemmens, J. S., Valkenburg, P. M., \& Gentile, D. A. (2015). The Internet Gaming Disorder Scale. Psychological Assessment, 27, 567-582. https://doi.org/10.1037/pas0000062

Li, D., Liau, A., \& Khoo, A. (2011). Examining the influence of actual-ideal self-discrepancies, depression, and escapism, on pathological gaming among massively multiplayer online adolescent gamers. Cyberpsychology, Behavior, and Social Networking, 14, 535-539. https://doi.org/10.1089/cyber.2010.0463

Matsuba, M. K. (2006). Searching for self and relationships online. CyberPsychology \& Behavior, 9, 275-284. https://doi.org/10.1089/cpb.2006.9.275

Müller, K. W., Janikian, M., Dreier, M., Wölfling, K., Beutel, M. E., Tzavara, C., \& Tsitsika, A. (2014). Regular gaming behavior and internet gaming disorder in European adolescents: Results from a cross-national representative survey of prevalence, predictors, and psychopathological correlates. European Child \& Adolescent Psychiatry, 24, 565-574. https://doi.org/10.1007/s00787-014-0611-2

Myers, D. G. (2009). Social psychology (10th ed.). New York: McGraw-Hill.

Newzoo. (2017). Newzoo's global games market report. Retrieved from https://newzoo.com/insights/articles/theglobal-games-market-will-reach-108-9-billion-in-2017-with-mobile-taking-42/

Peng, W., \& Liu, M. (2010). Online gaming dependency: A preliminary study in China. Cyberpsychology, Behavior, and Social Networking, 13, 329-333. https://doi.org/10.1089/cyber.2009.0082

Pontes, H. M., Macur, M., \& Griffiths, M. D. (2016). Internet gaming disorder among Slovenian primary school children: Findings from a nationally representative sample of adolescents. Journal of Behavioral Addictions, 5, 304310. https://doi.org/10.1556/2006.5.2016.042

Porter, G., Starcevic, V., Berle, D. \& Fenech, P. (2010). Recognizing problem video game use. Australian and New Zealand Journal of Psychiatry, 44, 120-128. https://doi.org/10.3109/00048670903279812

Przybylski, A. K., Weinstein, N., Murayama, K., Lynch, M. F., \& Ryan, R. M. (2012). The ideal self at play: The appeal of video games that let you be all you can be. Psychological Science, 23, 69-76.

https://doi.org/10.1177/0956797611418676

Quinones, C., \& Kakabadse, N. K. (2015a). Self-concept clarity and compulsive Internet use: The role of preference for virtual interactions and employment status in British and North-American samples. Journal of Behavioral Addictions, 4, 289-298. https://doi.org/10.1556/2006.4.2015.038

Quinones, C., \& Kakabadse, N. K. (2015b). Self-concept clarity, social support, and compulsive Internet use: A study of the US and the UAE. Computers in Human Behavior, 44, 347-356.

https://doi.org/10.1016/j.chb.2014.11.019

Rehbein, F., Kliem, S., Baier, D., Mößle, T., \& Petry, N. M. (2015). Prevalence of Internet Gaming Disorder in German adolescents: Diagnostic contribution of the nine DSM-5 criteria in a state-wide representative sample. Addiction, 110, 842-851. https://doi.org/10.1111/add.12849

Saunders, J. B., Hao, W., Long, J., King, D. L., Mann, K., Fauth-Bühler, M., ... Chan, E. (2017). Gaming disorder: Its delineation as an important condition for diagnosis, management, and prevention. Journal of Behavioral Addictions, 6, 271-279. https://doi.org/10.1556/2006.6.2017.039

Smahel, D., Blinka, L., \& Ledabyl, O. (2008). Playing MMORPGs: Connections between addiction and identifying with a character. CyberPsychology \& Behavior, 11, 715-718. https://doi.org/10.1089/cpb.2007.0210 
Tajfel, H., \& Turner, J. C. (1985). The social identity theory of intergroup behavior. In S. Worchel \& W. G. Austin (Eds.), Psychology of intergroup relations (pp. 7-24). Chicago: Nelson-Hall.

Turner, N. E., Paglia-Boak, A., Ballon, B., Cheung, J. T., Adlaf, E. M., Henderson, J., \& Mann, R. E. (2012). Prevalence of problematic video gaming among Ontario adolescents. International Journal of Mental Health and Addiction, 10, 877-889. https://doi.org/10.1007/s11469-012-9382-5

Xu, Z., Turel, O., \& Yuan, Y. (2012). Online game addiction among adolescents: Motivation and prevention factors. European Journal of Information Systems, 21, 321-340. https://doi.org/10.1057/ejis.2011.56

Yee, N. (2006). Motivations for play in online games. CyberPsychology \& Behavior, 9, 772-775.

https://doi.org/10.1089/cpb.2006.9.772

Zanetta Dauriat, F., Zermatten, A., Billieux, J., Thorens, G., Bondolfi, G., Zullino, D., \& Khazaal, Y. (2011).

Motivations to play specifically predict excessive involvement in Massively Multiplayer Online Role-Playing

Games: Evidence from an online survey. European Addiction Research, 17, 185-189.

https://doi.org/10.1159/000326070

\section{Correspondence to:}

Renata Glavak-Tkalić

Institute of Social Sciences Ivo Pilar

10000 Zagreb

Croatia

E-mail: renata.glavak.tkalic(at)pilar.hr

Editorial record: First submission received on June 6, 2017. Revisions received on April 30, 2018 and June 8, 2018, Accepted for publication on June 18, 2018.

\section{About Authors}

Berislav Šporčić received an MA degree in psychology from the Department of Psychology at the Croatian Studies at the University of Zagreb, Croatia. His primary research interests are gaming, addiction, and psychopathology. Currently, he is doing an internship at the Department for Forensic Psychiatry of the University Psychiatric Hospital Vrapče, Zagreb and is a PhD student at the University of Split School of Medicine.

Renata Glavak-Tkalić, PhD, is a Senior Research Associate at the Institute of Social Sciences Ivo Pilar, Zagreb, Croatia. She is also an Assistant Professor of Psychology of Addiction in the Department of Psychology at the Croatian Studies at the University of Zagreb, Croatia. Her research interests focus on the psychology of drug (ab)use and addiction, gambling, gaming, psychopathology, adolescent problems, interpersonal acceptance and rejection, and cross-cultural research. 